Editorial

\title{
More Research Is Necessary to Establish the Ergogenic Effect of Caffeine in Female Athletes
}

\author{
Juan José Salinero ${ }^{\circledR}$, Beatriz Lara, Ester Jiménez-Ormeño, Blanca Romero-Moraleda,

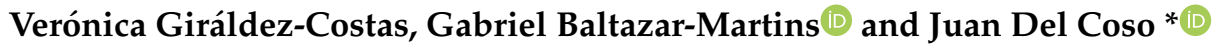 \\ Exercise Physiology Laboratory, Camilo José Cela University, 28692 Madrid, Spain \\ * Correspondence: jdelcoso@ucjc.edu; Tel.: +34-9185-3131
}

Received: 9 July 2019; Accepted: 12 July 2019; Published: 15 July 2019

Dear Editor-in-Chief,

Today, there is a significant gap in research on the ergogenicity of caffeine, and on sports nutrition in general: the benefits/drawbacks for a given substance are typically assumed for the whole population of athletes when most of the evidence is supported by investigations with only male samples. As a result of this assumption, acute pre-exercise ingestion of $3-9 \mathrm{mg} / \mathrm{kg}$ of caffeine is considered an effective strategy to increase sports performance [1], while data on urine caffeine concentration indicates that the use of caffeine in sport is similar in both sexes [2]. A few recent investigations using women as study samples, have also found that caffeine increases sports performance [3-6]. However, evidence regarding the overall ergogenicity of caffeine in women is much scarcer than in men, and it seems unsafe to conclude that the ergogenic effect of a moderate dose of caffeine is of similar magnitude in men and women.

A search for published studies on the effects of caffeine on physical performance in PubMed and Scopus, following with the Preferred Reporting Items for Systematic Review and Meta-Analyses (PRISMA) guidelines [7], showed a total of 362 original investigations that have compared caffeine to a placebo/control situation, with the measurement of at least one physical performance variable (Figure 1).

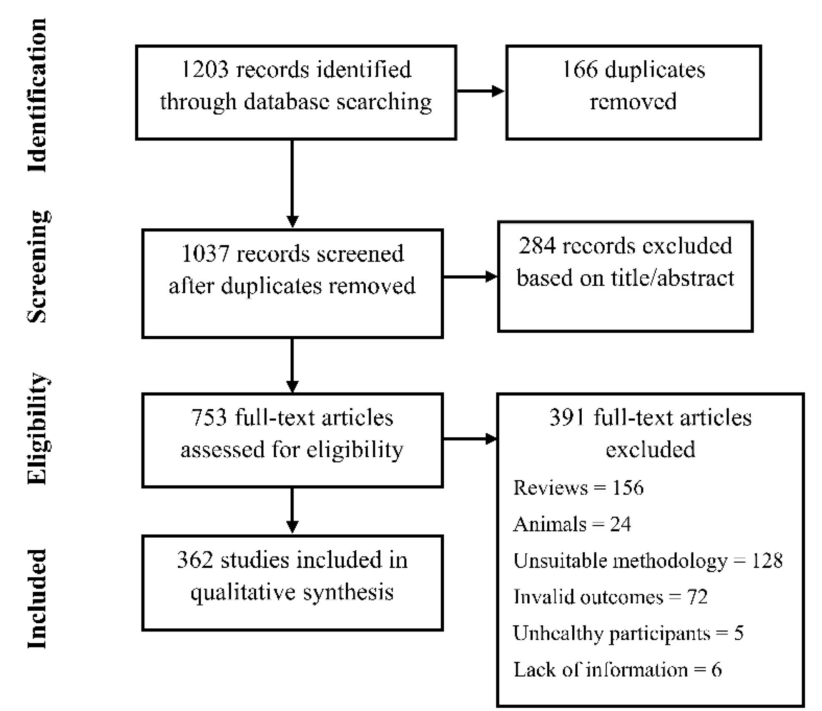

Figure 1. Selection of studies.

After filters were applied to remove duplicates or publications with unsuitable methodology, the search illustrated that a total of 5321 individuals have been tested to assess caffeine ergogenicity, 
since the seminal investigation by Costill et al. [8]. From this sample, 703 participants were women, which represents only $13.2 \%$ of the total sample.

Although investigations on this topic have a higher tendency to include women, especially since 2013, women still represent only 16.3\% of individuals participating in research carried out in 2018 (Figure 2). In addition, there is no investigation that has measured caffeine ergogenicity in women with doses below $1 \mathrm{mg} / \mathrm{kg}$ or above $9 \mathrm{mg} / \mathrm{kg}$, and the number of women in investigations about caffeine effects on speed and muscle power is very low (Table 1 ).

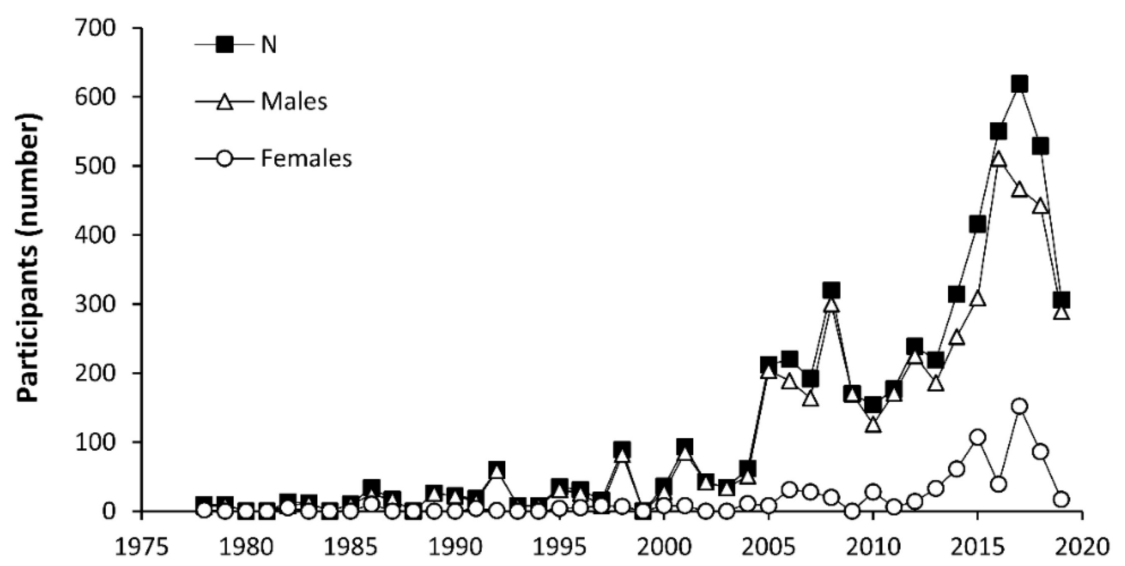

Figure 2. Evolution of the number of participants ( $n=$ total, males and females) in investigations aimed at determining the ergogenic effects of caffeine.

Table 1. Number (frequency) of male and female participants in investigations aimed at determining the ergogenic effects of caffeine depending on dose, type of exercise, and participant's level.

\begin{tabular}{cccc}
\hline & & Males & Females \\
\hline \multirow{5}{*}{ Caffeine dose } & $<1 \mathrm{mg} / \mathrm{kg}$ & $10(100.0 \%)$ & $0(0.0 \%)$ \\
& $1.0-2.9 \mathrm{mg} / \mathrm{kg}$ & $608(90.2 \%)$ & $66(9.8 \%)$ \\
& $3.0-5.9 \mathrm{mg} / \mathrm{kg}$ & $2295(85.2 \%)$ & $400(14.8 \%)$ \\
& $6.0-9.0 \mathrm{mg} / \mathrm{kg}$ & $1590(87.0 \%)$ & $237(13.0 \%)$ \\
& $>9 \mathrm{mg} / \mathrm{kg}$ & $115(100.0 \%)$ & $0(0.0 \%)$ \\
\hline Type of exercise & Speed & $128(89.5 \%)$ & $15(10.5 \%)$ \\
& Strength & $527(83.1 \%)$ & $107(16.9 \%)$ \\
& Power & $98(83.8 \%)$ & $19(16.2 \%)$ \\
& Anaerobic-like & $587(88.0 \%)$ & $80(12.0 \%)$ \\
& Endurance-like & $2019(89.0 \%)$ & $249(11.0 \%)$ \\
& Team-sport & $241(70.9 \%)$ & $99(29.1 \%)$ \\
Athlete' level & Other & $1018(88.4 \%)$ & $134(11.6 \%)$ \\
& Trained & $2777(87.8 \%)$ & $385(12.2 \%)$ \\
& Active & $1421(85.7 \%)$ & $237(14.3 \%)$ \\
& Untrained & $420(83.8 \%)$ & $81(16.2 \%)$ \\
\hline
\end{tabular}

Interestingly, there are no investigations measuring the ergogenic effect of caffeine during the different phases of the menstrual cycle, despite the interactions between caffeine and female sex hormones [9]. In fact, it has been found that the effect of caffeine on increasing blood pressure is higher in the follicular than in the luteal phase in female adolescents [10]. All this information indicates that it is still too early to establish that women experience the same ergogenic response to caffeine as men, and further research is needed to describe the optimal conditions of caffeine use in sport and exercise for women. With this Editorial, we want to encourage authors to provide objective information about the dose-effect of caffeine on female athletes' physical performance. We also want to embolden research focused to determine the magnitude of the ergogenic effect of caffeine during the different phases of the menstrual cycle. The Nutrients' Special Issue on "Coffee and Caffeine Consumption for 
Human Health" is open to receive investigations on these topics that hold to "bridge the gap" on the ergogenicity of caffeine in female athletes.

Author Contributions: Conceptualization, J.D.C.; methodology, J.J.S., B.L., E.J.-O., B.R.-M., V.G.-C., and G.B.-M.; formal analysis, J.J.S., and J.D.C.; writing—original draft preparation, J.D.C.; writing—review and editing, J.J.S., B.L., E.J.-O., B.R.-M., V.G.-C., and G.B.-M; supervision, J.D.C.

Funding: This research received no external funding.

Acknowledgments: We want to acknowledge all the authors that are investigating the effects of acute caffeine intake in several aspects of physical performance.

Conflicts of Interest: The authors declare no conflict of interest.

\section{References}

1. Baltazar-Martins, J.G.; Brito de Souza, D.; Aguilar, M.; Grgic, J.; Del Coso, J. Infographic. The road to the ergogenic effect of caffeine on exercise performance. Br. J. Sports Med. 2019. [CrossRef] [PubMed]

2. Aguilar-Navarro, M.; Muñoz, G.; Salinero, J.J.; Muñoz-Guerra, J.; Fernández-Álvarez, M.; Plata, M.D.M.; Del Coso, J. Urine Caffeine Concentration in Doping Control Samples from 2004 to 2015. Nutrients 2019, 11, 286. [CrossRef] [PubMed]

3. Lara, B.; Gonzalez-Millán, C.; Salinero, J.J.; Abian-Vicen, J.; Areces, F.; Barbero-Alvarez, J.C.; Muñoz, V.; Portillo, L.J.; Gonzalez-Rave, J.M.; Del Coso, J. Caffeine-containing energy drink improves physical performance in female soccer players. Amino Acids 2014, 46, 1385-1392. [CrossRef] [PubMed]

4. Del Coso, J.; Portillo, J.; Muñoz, G.; Abián-Vicén, J.; Gonzalez-Millán, C.; Muñoz-Guerra, J. Caffeine-containing energy drink improves sprint performance during an international rugby sevens competition. Amino Acids 2013, 44, 1511-1519. [CrossRef] [PubMed]

5. Pérez-López, A.; Salinero, J.J.; Abian-Vicen, J.; Valadés, D.; Lara, B.; Hernandez, C.; Areces, F.; González, C.; Del Coso, J. Caffeinated energy drinks improve volleyball performance in elite female players. Med. Sci. Sports Exerc. 2015, 47, 850-856. [CrossRef] [PubMed]

6. Skinner, T.L.; Desbrow, B.; Arapova, J.; Schaumberg, M.A.; Osborne, J.; Grant, G.D.; Anoopkumar-Dukie, S.; Leveritt, M.D. Women Experience the Same Ergogenic Response to Caffeine as Men. Med. Sci. Sports Exerc. 2019, 51, 1195-1202. [CrossRef] [PubMed]

7. Moher, D.; Liberati, A.; Tetzlaff, J.; Altman, D.G. Preferred Reporting Items for Systematic Reviews and Meta-Analyses: The PRISMA Statement. PLoS Med. 2009, 6, e1000097. [CrossRef] [PubMed]

8. Costill, D.L.; Dalsky, G.P.; Fink, W.J. Effects of caffeine ingestion on metabolism and exercise performance. Med. Sci. Sports 1978, 10, 155-158. [PubMed]

9. Arnaud, M.J. Pharmacokinetics and Metabolism of Natural Methylxanthines in Animal and Man. Handb. Exp. Pharmacol. 2011, 33-91. [CrossRef]

10. Temple, J.L.; Ziegler, A.M. Gender Differences in Subjective and Physiological Responses to Caffeine and the Role of Steroid Hormones. J. Caffeine Res. 2011, 1, 41-48. [CrossRef] [PubMed]

(C) 2019 by the authors. Licensee MDPI, Basel, Switzerland. This article is an open access article distributed under the terms and conditions of the Creative Commons Attribution (CC BY) license (http://creativecommons.org/licenses/by/4.0/). 